\title{
Building trust in persuasive gerontechnology: User-centric and institution-centric approaches
}

\author{
Faridun Sattarov $\mathrm{PhD}^{\mathrm{a}}$ \\ Saskia Nagel $\mathrm{PhD}^{\mathrm{a}, \mathrm{b}, *}$
}

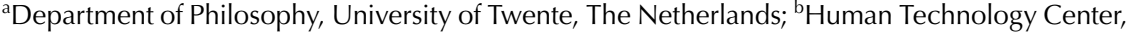
RWTH Aachen University, Theaterplatz 14, 52062 Aachen, Germany; *Corresponding author: saskia.nagel@humtec.rwth-aachen.de
\end{abstract}

\begin{abstract}
F. Sattarov, S. Nagel. Building trust in persuasive gerontechnology: User-centric and institution-centric approaches. Gerontechnology 2019;18(1):1-14; https://doi.org/10.4017/ gt.2019.18.1.001.00 Trust in technology is an important factor for the design and use of technology in general. While there is growing interest in the role of trust on this general level, so far little attention has been given to the particularities of trust in persuasive technologies, i.e. technologies that serve to persuade users into certain behaviours. Those technologies are increasingly targeting the older adults, posing ethical questions that ask for sensitive investigation of trust. Here, we explore the specific character of trust in persuasive gerontechnology. We argue that the question of how to establish trust in technology, how to make trust lasting and enduring, requires considering user-centric and institution-centric approaches, and suggest an approach that is sensitive to wider social and institutional factors. The impact that persuasive gerontechnology can have depends on whether people can trust them, the designers, or the overall system. Drawing on studies of determinants of institutional trust, we identify four main strategies that can inform designers, technology assessors and policy makers in building trust between technology and users: (1) creating novel institutions, (2) creating incentives, (3) providing guarantees, and (4) ensuring transparency. We conclude the discussion with suggestions regarding future directions in researching trust and persuasive technology.
\end{abstract}

Keywords: trust, persuasive technology, gerontechnology, e-health, institutions

\section{INTRODUCTION}

The global human population is ageing, and the rate of population aging is predicted to increase in the coming decades (Lutz et al. 2008; Oeppen \& Vaupel 2002). This is considered to be one of the most notable global demographic trends of this century (United Nations 2013; WHO 2015). Population aging has serious implications for healthcare provision including higher demand for long-term care, housing infrastructure, and social and economic resource allocation (Tinker 2002). Older people are increasingly facing lack of companionship and loneliness (Cattan et al. 2005), as well as higher dependence on families and local communities (Thommessen et al. 2002; Garlo et al. 2010; Etters et al. 2008). As mirrored by the World Health Organization's pronouncement that "years have been added to life and now the challenge is to add life to years" (Mollenkopf \& Walker 2007, p. 3), there are concerns about wellbeing and quality of life among the older adults (Mckee et al. 2012; WHO 2012; Drewnowski \& Evans 2001). Social and economic issues concerning population aging have become an object of public policy concern.

Some of the issues (while by far not most) faced by older people today can be met by bringing about behavioural changes with regard to life style, dietary and exercise habits (Andrews 2001), or adherence to prescribed medication treatment, while other issues can be overcome by sustaining existing 'good' habits, such as partaking in leisure and social activities (Mckee et al. 2012; Fozard \& Kearns 2006; Intille 2004). Creating and maintaining such healthy habits can become difficult for older people, amongst others due to their natural decline in physical and cognitive performance (James et al. 2011; Hébert 1997). Bringing about such behavioural changes can also become difficult because of shifting attitudes to cost-benefit ratios in old age (Melenhorst 2002), or the increasing chance of depression among older people (Penninx et al. 2000).

To answer these concerns, there has been a growing interest in the design and use of persuasive gerontechnology (hereinafter PGT) - technologies that are designed and used to bring about desired behavioural and life-style changes in older people (de Kort et al. 2005; Intille 2004; Sorri \& 
Leinonen 2008). PGTs are a product of the confluence of two recent technological trends: (1) "gerontechnologies" - technologies that target the various social, physical and healthcare needs of older people (e.g. Fozard et al. 2000; Bouma et al. 2007, 2009; van Bronswijk et al. 2009), and (2) "persuasive technologies" - technologies that are intentionally designed to affect and alter their users' behaviour (e.g. Fogg 2003; Lockton et al. 2008). In combining elements of these two technological trends, PGTs promise to become a positive force for motivating and assisting older users to engage in healthy life-styles and behaviours. For instance, PGTs can monitor various aspects of relevant behaviours such as medication intake, nutrition, exercise, or social interaction. Moreover, such technologies can intervene in a variety of ways, for example, by providing timely feedback and advice, by making the target behaviours easier to perform, or by rewarding desirable actions and discouraging potentially harmful ones (de Kort et al. 2005).

The successful implementation of PGT invariably depends on the amount of trust that people place in them. A persuasive technology is unlikely to have the desired persuasive effect unless it is found to be trustworthy by its users and thus accepted as a personalized technology in the home or at the body in the first place. This suggests that developments to introduce novel PGTs should be accompanied by processes of building trust in them. This is in the interest of different stakeholders, including users, technology developers, and healthcare providers. Thus, the notion of trust plays an important role in the ethical and policy deliberations on the design and use of PGTs.

While there has been a growing interest in the nexus between trust and technology (Nickel, Franssen \& Kroes 2010; Åm 2011; Nickel 2011, 2013, 2015; Nickel \& Spahn 2012; Hu et al. 2016; Voerman \& Nickel 2017; McCall \& Baillie 2017; Allen 2018) surprisingly little explicit attention has been given to what we call the socialinstitutional character of trust. Trust is generally essential for ordering and normalising social relations within society (Barnes 1988; Luhmann 1979). The social-institutional character of trust concerns the creation of rules, norms, and practices that can make trust in a specific social entity an enduring feature of social reality. In this paper, we aim to examine how trust can be built and maintained in the context of developing and introducing PGTs. We aim to understand the social-institutional aspect of trust in technology, not just because we are interested in knowing whether or not a specific instantiation of trust in technology is morally justified, but also because we need to better understand how broader institutional and societal factors can influence trust- ing attitudes toward technology, and thus inform ethical deliberation concerning trust in PGT.

By stressing the importance of user values and interests, as well as the role of institutions in building trust in technology, we suggest 'user-centric' and 'institution-centric' approaches to building trust in PGT. The former approach assesses the trustworthiness of a technical artefact by examining the extent to which its technical structure and properties support or undermine the values and interests of users. The latter approach evaluates the trustworthiness of a given technology by examining the overall institutional context in which the technology is embedded. We draw attention to the social and institutional aspects of trust in PGT and raise awareness that attempts aimed at building trust in technology can be misplaced unless such attempts are also accompanied by appropriate social and institutional policies.

The structure of the paper is as follows: Section 2 outlines some of the recent developments and uses of PGTs in the context of care for older people; Section 3 focuses on the relevance of trust for the development and implementation of PGTs by considering how trust can help address several practical and ethical concerns stakeholders might have about these technologies; Section 4 argues that the development of trustworthy PGTs must be accompanied by an approach to trust that is sensitive to wider social and institutional factors; While sections 5 and 6 further elaborate on the social and institutional approaches to trust respectively.

\section{Potential beNefits OF PeRSUASIVE GeronteChNOLOGY} The potential of PGTs for the older people lies in the various ways in which persuasive technologies can be used to appropriately maintain and enhance the physical, cognitive and social functioning of older people. For example, Fozard and Kearns (2006) have identified five main domains of human activity, where PGTs can be of help: (1) health and self-esteem, (2) housing and daily activities, (3) communication and governance, (4) mobility and transport, as well as (5) work and leisure. They also distinguish among four ways in which PGTs can intervene in the above domains: (1) enhancement and satisfaction, (2) prevention and engagement, (3) compensation and assistance, as well as (4) care and organization. Fozard and Kearns' analysis of the possible uses of PGTs suggests a rich variety of practical benefits such gerontechnologies can offer to older people.

At the level of physical functioning, there have been several technological developments to enhance the physical wellbeing of older people. Regular physical activity is crucial not only for physical but also for psychological wellbeing. 
While older people can find it challenging to exercise outdoors, they can be demotivated to do so alone at home. In this regard, so-called 'exergames', games with motion sensors and remote controls that require the players to move, can motivate older users to increase physical activity (Brox \& Hernández 2011), with research and development in this area being one of the most active (Matthews et al 2016). In playing the 'Skiing Game', developed by Finnish designers, the older players move their arms forward and backward to ski and move their body sideways to avoid obstacles in the game (Pyae et al. 2017). Similarly, an application such as QueFaire (Ponce et al. 2015) can help improve the physical well-being of senior people by recommending physical and social activities based on their pre-recorded preferences.

PGTs can also benefit older people in terms of their cognitive well-being. For example, while the effectiveness of medication in slowing the progress of dementia can depend on timely intake of appropriately prescribed medication, impaired cognition can negatively affect older people's ability to follow their prescribed medication regime (Elliott et al. 2015). Kamimura and Ishiwata (2012) describe how an automatic pill dispenser that reminds users to take their medication through audible and visual stimuli can be effective in enhancing medication adherence in older people with mild dementia. Similarly, a 'medical internet of things' (Dimitrov 2016) consisting of devices that monitor and track health indicators and real-time health data when a patient self-administers a therapy can be used for the prevention and management of chronic conditions. PGTs can also be used for improving the performance of other kinds of cognitive tasks, e.g., driving (Ruer et al. 2016).

Besides enhancing and maintaining physical and cognitive abilities in older people, PGTs can also be used for promoting much needed social wellbeing. For example, an ICT-based system designed for older people by the MELCO project (available online: www.melco.cs.ucy.ac.cy) promises to help increase social activities by building a virtual social network for seniors and their close social relations. Older people can also communicate with a "virtual imaginary interlocutor", given that such interlocutors can be of some help as a form of social-psychological support (Pasikowska et al. 2013). Similarly, more recent research and development activities have focused on virtual assistive companions (Tsiourti et al. 2016) and social robotic assistants for older users (Kellmeyer et al. 2018).

While PGT holds great promise for users, there are concerns relating to the ethics of persuasion and influence in general (for a thorough investi- gation, see Niker 2017, Atkinson (2006), Spahn (2012), Nagenborg (2014)). For example, using certain persuasive techniques, such as in the widely discussed 'nudging' (Thaler \& Sunstein 2008), may not bring about changes in the "general preference structure" of a person, potentially resulting in a "fragmented self" or "infantilisation" (Bovens 2009, p. 207-219). Doubtlessly, further research is needed to address such concerns, e.g., by identifying different forms of persuasion, influences, and nudges in order to facilitate nuanced ethical deliberations and policy options (Hansen \& Jespersen 2013). Other ethical concerns relate to potentially paternalistic and even patronising character of persuasion (Ijsselsteijn et al. 2006; Spahn 2012). However, recent discussions on 'relational autonomy' and 'ecologies of trust' suggest that seemingly paternalistic interventions within specific patient-physician or senior-caregiver relationships may be permissible or even desirable for reasons of their strengthening trusting relationships (Mackenzie \& Stoljar 2000; Niker \& Specker Sullivan 2018, Nagel in press). Hence, one way to address ethical concerns about persuasive technologies is to consider whether older users or their guardians can genuinely trust such technologies.

\section{TOWARD tRUST-BASED APPROACHES TO PERSUASIVE GERONTECHNOLOGY}

To further advance the debate on the ethics of persuasive technologies in general, and that of PGTs in particular, here we propose a distinct trustbased ethical approach to PGTs; an approach that recognises the concept of trust as a key tool for addressing the ethical and social issues arising from the development and use of PGTs. In the remainder of this section, we will first outline the core conception of trust on which we base our discussion of trust in PGT (Subsection 3.1), and will then elaborate on the relevance of trust for developing and introducing PGT (Subsection 3.2).

\section{Framing trust as shared values and interests be- tween designers and users}

Trust can be understood as a psychological or normative stance, disposition or attitude that others (whether a person, institution or entity) will act or behave in a predictable manner that respects one's values and interests (Barnes 1988, p. 34; Hardin 2002). On this understanding, a trusting attitude is formed on the basis of beliefs and expectations about the potential actions of others. These beliefs and expectations can be of two types: (1) predictive beliefs about how others will act; and (2) normative beliefs about how others should act (Nickel 2013).

The trusting person's expectations about the trusted person's behaviour and actions originate from the trusting person's assessment of the trusted 
person's interests and motivations; that is, A trusts $B$ with regard to $x$, insofar as $B^{\prime}$ s interests incorporate A's interests (Hardin 2002; see also McLeod 2002). On this view, trust stems from the perception or belief that the interests of the trusted person respect those of the trusting person: if the values and interests of a person whom we trust do not conform to our values and interests, then our trust in that person cannot be rationally justified (Hardin 2002). Our expectations about how others will or should behave are thus stem from our interpretation of other people's values and interests, which can be communicated through or gleaned from people's and institutions' reputation, their past and present behaviour, as well as shared understanding of norms, roles and responsibilities (Cook 2005).

In discussing trust, Sissela Bok noted: "whatever matters to human beings, trust is the atmosphere in which it thrives" (Bok 1979, p.33). Sharing the image of trust as an atmosphere, Baier describes "exploitation and conspiracy, as much as justice and fellowship, thrive better in an atmosphere of trust. There are immoral as well as moral trust relationships" (Baier 1986, pp. 231-2). Hence, we argue, from a moral perspective, the goal of building trust in PGT should also include the protection of trust from exploitation through institutional measures in a socially responsible manner.

\section{The importance of trust for developing persua- sive gerontechnology}

Our trust-based approach to PGTs is supported by the growing recognition of the concept of trust within moral philosophy and applied ethics. The notion of trust appears to have been commonplace within medical ethics before the 1970s (Hall 2005). However, with the shift of focus on patients' rights and autonomy, trust became often associated with paternalism (Churchill 1989; $\mathrm{O}^{\prime}$ Neill 2002). Sherlock, for example, perceives that "the language of rights and the language of trust move in opposite directions from one another" (Sherlock 1986). However, Hall (2005) observes trust in physicians and medical institutions currently gaining ground in medical ethics, law, and public policy. This process, according to Hall, is due to two main factors. Firstly, there has been a renewed interest in trust as a consequence of the trend towards managed care. Secondly, there has been a softening of opposition to traditional principles such as trust, as a result of growing scepticism about the suitability of purely autonomy and rights-based approaches to medical ethics (Nagel 2015; Nedelsky 1989). With respect to the latter development, interest in the concept of trust seems to be in accord with recent innovative ethical approaches that focus not so much on specific actions and events but more on relationships (Mackenzie \& Stoljar 2000; O'Connor \&
Nagel 2017). Notably, accounts of relational autonomy (Christman 2004; Friedman 2000; Mackenzie, Rogers, \& Dodds 2014; Meyers 2005) do justice to the understanding that we are socially embedded by being in constant interaction with others. Recognizing the role of trust does not preclude autonomy-based approaches, since as for example Wiesemann (2016) convincingly shows, trust can complement autonomy in a dialectical way - trust and autonomy "inform, balance, limit and change each other" (p. 12).

Building on this general motivation, the relevance of trust for the development and implementation of PGTs can be further gathered from the following five considerations:

(1) PGTs share important features with so-called 'direct computer-patient interfaces' - ICT-based systems that gather data pertaining to their users' health, habits, and lifestyle, derive inferences from the gathered data, and provide information or recommendation to the users based on these inferences, thus assisting (or in some cases, substituting) certain functions traditionally performed by clinicians and physicians. In this context, it has been argued (Nickel 2011) that developers of such systems must provide evidence for trustworthiness of their products at least insofar as users entrust them with intimate and confidential information and data on their health performance and habits, and life-style.

(2) Some empirical studies (e.g. Siegrist 2000, 2007) have found that trust in the institutions is a cause of acceptability of new technologies (i.e. the causal view), while others have found trust to be an indicator or expression of such acceptability (i.e. the associationist view) (Poortinga \& Pidgeon 2005). Both views suggest that trust is strongly related to the acceptability of novel innovations and support the idea that trust facilitates the acceptability of technology. Thus, trust is not only of ethical concern, but it is also of crucial practical concern for persuasive technology developers and other stakeholders.

(3) A growing number of studies in the field of captology (i.e. the study of persuasive technology, as coined by Fogg (2003)) have found that persuasive technologies with anthropomorphic features can more effectively induce behavioural change in users when compared to technologies without such features (e.g. Fogg 2003; Pak et al. 2012). These findings suggest that developers of such persuasive technologies can exert greater influence and power over their users. Moreover, according to Nickel and Spahn (2012), persuasive technologies can asymmetrically influence users' behaviour. Such possibilities raise questions such as, under what conditions older users are justified in trusting the motives, actions, and goals of those behind the persuasive technology (Berdichevsky \& Neuenschwander 1999). 
(4) PGTs are increasingly being offered to older individuals in the form of health monitoring and coaching via web-based e-health and telecare systems (Larburu et al. 2013; Lin 2013). While such services can help older patients to acquire habits and skills in managing their chronic conditions, they can also shift relations of trust by introducing new actors and entities (such as technological service providers) into the traditional context of care, thereby reducing the role of institutional caregivers, such as physicians and nurses (Voerman \& Nickel 2017; Hall 2005). Whereas in a traditional clinical setting, patients generally trusted their physicians if they perceived them as trustworthy, should this trust now also be extended to new actors and entities in the context of managed care? Such questions place trust at the foreground of ethical and policy deliberations on PGTs.

(5) PGTs, as novel technologies might also give rise to various kinds of anxieties, concerns, and feelings of uneasiness in older individuals, especially with regard to being observed or manipulated by technology. Older users of PGTs can, for instance, become concerned about the impact on their self-determination, their privacy, as well as the safety and security of their data and personal information (Sorell 2011; Sorell \& Draper 2012; Berridge 2016, 2017). In this respect, many such anxieties and concerns could be remedied through activities aimed at building and maintaining trusting relations and attitudes toward relevant persuasive technologies. This and above considerations suggest that processes of developing and introducing novel PGTs should be accompanied by processes of building and maintaining justified trust in such technologies.

\section{USER-CENTRIC AND INSTITUTION-CENTRIC APPROACHES} TO BUILDING TRUST IN PERSUASIVE GERONTECHNOLOGY How can one tell whether a certain kind of PGT is trustworthy? Earlier we have noted that our trusting beliefs and expectations about other people and institutions stem from our assessment of their interests, values, and motivations (that is, A trusts $B$ with regard to $\mathrm{x}$, insofar as B's interests incorporate A's interests (Hardin 2002)). On this view, we trust others who share and support our interests and values. But how can we tell whether a particular technology 'shares' and supports our interests and values? Although artefacts, systems, and applications cannot be said to possess interests and values in the same way as (rational) humans possess them, they can be attributed certain features and properties that can help us assess the extent to which particular technologies can support or undermine human interests and values. This possibility can form the basis on which to evaluate the trustworthiness of technologies. On this approach, in order to assess the trustworthiness of a specific PGT, it would be necessary to examine its technical properties (e.g. hardware and software features; end-to-end encryption); specific psychological means employed by the technology (i.e. kinds of cognitive, behavioural, or affective techniques; e.g. coercive vs. persuasive); particular functions and goals ascribed to the technology, and to assess the extent to which these factors can support or betray relevant older user interests and values. The findings of such an assessment carried out either by the developers or competent third-party experts, can then be communicated to end users or their representatives via appropriate means.

This approach builds on the thesis that technology can involve interests, values and norms, a thesis that has long been at the centre of the philosophy and ethics of technology and Science and Technology Studies (STS) (Winner 1980; Verbeek 2005; Brey 2008; Franssen 2009). Inquiries into the value-ladenness and normativity of technological artefacts have been the aim of various research endeavours, such as value sensitive design (Friedman et al. 2013), the disclosive computer ethics (Brey 2000), reflective design (Sengers et al. 2005), engineering ethics (Van de Poel \& Verbeek 2006) to name a few. These approaches suggest that engineers and designers can translate various stakeholder interests, values, and norms into material design specifications and software algorithms. Importantly, they can be adopted in evaluating the trustworthiness of PGTs by examining and evaluating whether and how such technologies promote or suppress the interests and values of users.

However, an attempt to ensure that an artefact conforms to user values and interests may run the risk of being designed in fragmented social and professional silos - that is, the scope of ethical deliberation can become limited to considerations of the technical parameters and functionality with lesser regard to concerns raised by the wider social, systemic, and institutional reality in which the artefact will be embedded once designed and marketed. One of the commonest cases cited in the literature on ethical and critical studies of technology are about artefacts and systems that (whether intentionally or not) end up reflecting the cultural worldview or economic interest of its designer more than the needs of the users for whom they were developed in the first place (Michelfelder et al. 2017). This can especially become commonplace with regard to the more marginalised, oppressed, or otherwise vulnerable segments of the population who through powerlessness of their own may have little influence or say in the design and development processes (Clarkson et al. 2013).

We propose that a combination of approaches that actively consider the importance of user val- 
ues and institutional factors in designing PGTs is crucial for developing and maintaining trust in these technologies. In ensuring trust in PGT, we recommend pursuing two lines of inquiry and practical action: (1) a user-centric line of inquiry and action, which involves technology designs that actively incorporate the interest, values and needs of older users and (2) an institutioncentric line of inquiry and action, which entails addressing and mitigating issues arising from the institutional context in which the PGT would operate. In Sections 5 and 6, we further clarify the user-centric and institution-centric approaches to building trust in PGT. Having elaborated on the two approaches, we conclude that the task of ensuring trust in PGT is an enterprise requiring not only the participation of the developers and end users but also involving multiple other stakeholder and interest groups such as technology assessors and ethicists, policy-makers, health-care providers and so on.

\section{THE USER-CENTRIC APPROACH TO BUILDING TRUST IN PGT: COMMUNICATION, PARTICIPATION, AND POSI- TIVE EXPERIENCE}

The user-centric approach to building trust in PGT emphasises the importance of active incorporation of the interests, values, and needs of older users in the design of PGT. On this approach, developers of PGTs should heed not only market indicators, but actively seek out the particular needs, values and interests of the target users (and in some cases of their guardians), as well as those of the wider community. As an ethical imperative, it stems from the burgeoning calls for socially responsible innovations and is necessitated by a number of considerations. For one, there can be issues of social, professional and generational difference between often younger designers and older users, which may preclude proper inclusion of the specific needs of older users in the design of the PGTs (Fozard \& Kearns 2006). Secondly, not all older people are alike in their needs, interests, and values. Obviously, healthy older users may have needs altogether different from those of physically or mentally frail people. Finally, another source of complexity is the potential conflict of interest among various stakeholders. For example, PGT may contribute to the autonomy of older people, and, to an extent, make them less dependent on institutional care, which would potentially go against the interest of private care services (e.g. Sorell 2011). Such concerns call for a nuanced understanding and balancing of the different needs, values, and interests of older people and other stakeholders, and their incorporation in the design of PGT.

The user-centric approach to building trust in PGT can comprise a few complimentary strate- gies for building trust in PGTs: (1) communication of shared values and interests; (2) participation of users in the design process; and (3) designing for positive user experience. These strategies are based on the principle that technical practices for designing trustworthy technologies, and their professional assessment, should be embedded in particular social and communal context of older users. They do not exhaust all the possible strategies, and some have been put in practice in certain design contexts for various reasons.

\section{Communication of shared values and interests}

One promising strategy for building trust in PGT is to communicate, to relevant users via appropriate means, that the technology in question (and their developers, for that matter) share the users' values and interests. This is warranted by the simple reason that one cannot reasonably expect older users to be in a position to make a technical assessment of the product in question, or be well-versed in the intricacies of, e.g., value sensitive design methodology. Expert technical or ethical assessment of the technology under consideration should be made accessible to users or their community, by stating in an honest and transparent manner, how the design of the technology addresses those issues and concerns held by the older users or their guardians. The need for such communication is further necessitated by the relational and institutional aspects of trust. Indeed, as a relational phenomenon, trust is not so much a property of an entity but of relationships among socially embedded actors (Lewis \& Weigert 1985; Christman 2004; Nagel 2015, in press; Coeckelbergh 2012; Darwall 2017; Niker \& Specker-Sullivan 2018); while, as an institutional phenomenon, trust often rests on expert advice, approval, or vouching (Luhmann 1979; Giddens 1990; Coleman 1990; Pettit 1995). Communication of shared values and interests often go hand in hand with marketing activities.

\section{Participation of users in the design processes}

Part of the challenge to design trustworthy PGTs is the difference in technology generation between (often) younger designers and older users (Fozard \& Kearns 2006). Hence, a second, complementary, strategy for building trust in PGT is to actually involve older users as key stakeholders in the process of design and development of the technology. For example, participatory design strives for an active inclusion of (technology) users in processes of research and development (Muller \& Kuhn 1993), where "the participants typically undertake the two principal roles of users and designers where the designers strive to learn the realities of the users' situation while the users strive to articulate their desired aims and learn appropriate technological means to obtain them" (Robertson \& Simonsen 2013, p. 2). Through such 
participation, older users can weigh in on the shared system of values and interests, on the basis of which the technology is to be developed. Allowing users to influence the design of persuasive technologies can help make those technologies more trustworthy by aligning the design specifications with the user expectations.

In view of these, recent research has focused on developing methods for involving older users in design processes, with proposals ranging from descriptive ethnographical to ethics-sensitive approaches. For example, Sergio Sayago and colleagues (2011a; 2011b) note that "the classical focus on cognitive aspects of individual users engaged in performing tasks efficiently is not sufficient to design better technologies" (2011a, p. 360). The authors instead emphasise the importance of "understanding the social contexts of system use and the experiences of people and ICT also comes into play", and argue that in researching the older users' experiences of and attitudes to ICT, the ethnographical methods can help highlight "the context of system use, social practices of interactions and communities' sensibilities" (ibid). Britt Östlund (2015) distinguishes different levels of participation by older users in design processes, ranging from the most active (e.g. older users being the drivers of innovation as co-actors) through the less active (e.g. older users contributing their views as consultants) to the least active (e.g. older users being objects of action and manipulation by others) forms of participation. These research findings suggest that employing participatory methods that are sensitive to both the actual context of technology use and the various levels of inclusive design can better inform the designers and other stakeholders about the interests, needs, and values of the older users.

\section{Designing for positive user experience}

Older users' experience of PGTs can affect their trust and acceptance of these technologies (Pal 2018; McMurray et al. 2017). Consequently, a third strategy for building trust in PGT is to design for positive user experience. One way to ensure positive user experience is undoubtedly to create user interfaces that are easy to use and adaptable to particular needs and preferences of older users. Fozard and Kearns (2006) note that technologies for hobbies and leisure activities have not been as popular among older users (as opposed to younger users), which can be a consequence of perceived difficulties and barriers due to physical and cognitive limitations (Keränen 2017). Cognitive and physical changes occurring in old age often include reduced attention span, diminished auditory and visual perception, as well as declines in memory and psychomotor coordination (Hawthorn 2000). Therefore, PGT user interfaces can be made more suitable to older users by in- cluding technical features such as simplified layouts (de Barros et al. 2014); input methods not requiring precise hand movements, including touch input (Harada et al. 2013), voice input (Wang et al. 2016), and linear methods of web navigation (Castilla et al. 2016); and context sensitive help options (Patsoule \& Koutsabasis 2014).

\section{THE INSTITUTION-CENTRIC APPROACH TO BUILDING TRUST IN PGT: LAWS, INCENTIVES, GUARANTEES AND TRANSPARENCY}

While the user-centric to the design of trustworthy PGT described in the previous section is important, it is not sufficient, for it should also be complemented by the institutional approach to building trust in technology, which we discuss in this section. The institutional approach to building trust in PGT emphasises the importance of considering how the institutional framework within which the technology operates can have implications for the trustworthiness of a given PGT. On this approach, designers and other relevant stakeholders should consider how legal, regulatory or policy factors can affect the ways in which users view their technologies as trustworthy, and the ability of relevant stakeholders to certify or decertify certain PGTs as trustworthy, as well as the very possibility of designing for trust in technology. For example, our trust in specific technologies can be affected by our trust in institutions that govern, regulate or certify these technologies (Siegrist 2000, 2007; Poortinga \& Pidgeon 2005). Hence, if a trusted institution (e.g. an association of gerontologists or national technology assessment agency) would attest to the untrustworthiness of some technology, it would plausibly have implications for the reputation of that technology as trustworthy. For example, an international consortium of data protection agencies led by the Canadian Data Protection Agency issued a letter of distrust concerning privacy features of the Google Glass, thereby affecting its spread (https://www.priv.gc.ca/en/opc-news/news-andannouncements/2013/nr-c_130618). On the same logic, why should we trust some persuasive application if we do not trust the national data protection laws in the first place? Nowadays, it would be hard to imagine older users being aware of or comprehending, the intricacies of applicable data protection laws. Yet, it is plausible that the absence of such normative frameworks can give rise to an atmosphere of social distrust within the general population, which can catch on with the community of older people. The European General Data Protection Regulation that has come into force in May 2018 (www.eugdpr.org), despite its current shortcomings, is a relevant step in this regard (The Economist 2018).

These examples suggest that considerations or recommendations of institutional nature may not 
be entirely within the scope of responsibility and practical action of individual engineers or designers. Following the moral dictum that 'ought' implies 'can' - meaning that one's obligations should not exceed one's power to perform those obligations - few, if anyone at all, would argue that an engineer whose sole purpose is to design a trustworthy PGT, is also responsible for the absence or shortcomings of regulatory or normative institutions. While some such institutional shortcomings might be addressed at the design level (e.g. issues posed by the absence of data protection laws could be mitigated at least to some extent, by the inclusion of end-to-end encryption in the PGT), there would remain numerous other issues that cannot be addressed by the designers. The task of dealing with such issues, therefore also befalls the wider community of stakeholders committed to the protection of the older adults. With regard to engineer's responsibility, it can be said that they should (1) strive the best they can to ensure that their products have technical capabilities to mitigate various potential risks posed by the larger system; and (2) to inform potential end users or their representatives of potential systemic or institutional risks in an honest and transparent manner, for indeed, clear and honest communication of, and transparency about the risks involved can go a long way in establishing mutual understanding and trust.

A more fundamental reason for examining the institutional character of trust concerns the nascent 'institutional turn' across the social sciences (Jessop 2001; Nielsen 2005), as a result of which there has been a growing recognition of the role of institutions in understanding how society works. The importance of the institutional perspective has been recognised in different research areas, including politics (Rhodes et al. 2006), economics (Searle 2005), geography (Jessop 2001), and ethics (Thompson 1999). Some first attempts have been made to adopt institutional approaches to matters concerning technology, by considering the role of institutions in promoting technological innovations (Nelson 2008), in building public trust in genetically modified crops (Poortinga \& Pidgeon 2005; Siegrist 2007), and in creating consumer trust in electronic commerce (GrabnerKräuter \& Kaluscha 2008).

In the area of gerontechnology, too, a number of recent studies have voiced support for the institutionally-sensitive and context-aware approaches to a wide variety of assistive technologies. Among others, Östlund and colleagues have argued that we "are used to focusing on the older patients" needs and the technical devices that they would use, not on the relation between themselves and the patients as a part of the context where technology is implemented" (2015, p. 87). Similarly,

Lee and Coughlin note that previous studies of older adults' technology adoption have focused on "detailed design and physical ease-of-use"; instead, they offer a more "holistic framework that covers social contexts of use and delivery and communication channels" (2014, p. 1). In this regard, applying social scientific approaches to issues of health and illness, according to Joyce and Loe, offers "an empirical basis from which to analyse technogenarians in action, as well as the stakeholders and institutions involved in the ageing, health, and technology matrix" (2010, p. 171).

Distinguishing 'user-centric' and 'institution-centric' approaches is thus not without precedent and corresponds to the distinction between 'functional' and 'sociotechnical' paradigms of innovations in the philosophy of engineering and design (e.g. Frohlich et al. 1997). For example, as Cozza and colleagues (2017) have put it, the functional paradigm emphasises "technical evaluations of the solutions to user problems", whereas the sociotechnical paradigm emphasises "the co-construction of new design trajectories, which could deal with the diverse and changing conditions of older life" (p. 609). Thus, while the user-centric approach considers issues faced by older users offering solutions at the level of technical artefacts, the institution-centric approach considers such issues in light of the entanglement of technical and institutional aspects and offers solutions at the level of sociotechnical systems and the wider society.

In the following subsections, we summarize recommendations for building and maintaining trust in PGTs, while drawing on a number of studies of determinants of institutional trust (Hardin 1991; Grabner-Kräuter 2002; Grabner-Kräuter \& Kaluscha 2008). We distinguish these suggestions and recommendations in the following categories: (1) creating novel institutions; (2) creating incentives; (3) providing guarantees; and (4) ensuring transparency.

\section{Creating novel institutions}

One strategy for building trust in PGT is to create novel institutions. Our trust in expert and technological systems is in great part built on the basis of certain rules, norms, and institutions that make such systems accountable and their inner workings transparent. When a flight passenger boards a plane, the passenger does so, on the basis of her trust that certain state sanctioned rules and norms are upheld in, say, training and employing pilots by airlines companies, and in the technical maintenance of the plane. Such rules, norms, and institutions for regulating technological systems are, however, applicable to technologies and systems that are largely predictable. However, in the case of highly interac- 
tive persuasive technologies, such as the ones that employ machine-learning algorithms, there can be relevant outcomes that could not be predicted by neither the designers nor the owners of such technologies. This suggests that in order to build trust in such technologies there is a need for institutions and norms whose sole purpose would be to deal with the unpredictable nature of such technologies. Such norms, rules, and institutions (e.g. the liability law) are needed to help prevent potentially harmful outcomes from occurring and remedy harms already caused.

\section{Creating incentives}

A well-recognised policy for strengthening institutional trust is to create various structural and institutional incentives that can help ensure trustworthy and honest behaviour among relevant institutional actors. Generally speaking, such incentives fall into two - positive and negative - categories: they can consist of rewards offered for good behaviour (i.e. positive incentives) and penalties imposed for reprehensible behaviour (i.e. negative incentives) on the part of institutional actors or entire institutions. In the case of PGTs, such institutional incentives (which can consist of threats of punishment or withdrawal of future rewards from the product designers and other relevant third-party stakeholders) can help ensure that it is in the designers or technical service providers interest to make their technologies and services reliable and trustworthy. This has been described by Hardin as "encapsulation of interests", which for Hardin is the main basis for grounding trust (1991). Certain social scientific accounts of trust that focus on the institutional character of trust can further support this view (Coleman 1990; Pettit 1995; also Nickel 2013).

\section{Providing guarantees}

Another policy for promoting trust in PGT involves the provision of guarantees for the products in question. Such guarantees can consist of contractual promises to compensate - partly or wholly - for potential damages or other negative consequences that cannot be ruled out in a preliminary manner (Grabner-Kräuter 2002). Such guarantees can cover possible returns, refunds, and monetary compensations. The importance of providing satisfactory guarantee options to users has been well-recognised, for example, in the context of online trust (Cheung \& Lee 2006; Gefen et al. 2003; Jarvenpaa et al. 2000; de Ruyter et al. 2001). Providing older users with such guarantee options can help decrease the risk in using PGT. The credibility of such guarantee options can greatly depend on the existing reputation of the technology or its designers and manufacturers, as well as on the perceived resources of the company that determine the enforceability of the promise embodied in the guarantees. Therefore, it is essential that the technology firm can back up its guarantee policies by adequate information and reputation policies (Grabner-Kräuter \& Kaluscha 2008). Furthermore, policy to provide guarantees can be made more effective if product designers and manufacturers also include known and trusted third-party institutions that can set strict requirements and standards for data privacy and the protection and security of data or transparency in the use of collectible data. Designers and producers of PGTs could legally bind themselves to satisfy such strict standards for collecting, storing, processing user data through security certificates under specific - national or regional - jurisdictions for data protection or product liability laws.

\section{Ensuring transparency}

Transparency can be broadly understood as referring to the extent of the willingness and the ability, of institutional bodies and actors, to offer information concerning, among others, the internal structure of their institutions, their decisionmaking mechanisms, and their policy choices (Hollyer et al. 2011). That institutional transparency can foster institutional trust has been noted in many domains of the social sciences (Frewer 2004; Frewer \& Salter 2007; Forssbæck \& Oxelheim 2015, pp. 11-14). Transparency has also implications for societal accountability (Bauhr 2010). In the context of PGTs, activities aimed at ensuring institutional transparency can engender users' trust in the technology as well as contribute to trusting relationships among the various stakeholders involved in it.

Instead of giving a passive access to the relevant information, in ensuring transparency the relevant institutions can take a proactive role by actually reaching out the community of older users and communicate the relevant information. In this particular regard, it might be useful to partition information to be communicated in terms of what Robert Audi calls "categories of expectation" (2007). Consider, for instance, the differences between saying "We hope do X", "We expect to do $X$ ", "We intend to do X", and "We will do X". The degree of commitment, as can be seen, increases with each next statement. We suggest that by observing such differences and choosing the appropriate language in their public relations, institutional actors and other relevant stakeholders would be less likely to alienate the public should they fail to perform the projected activities.

\section{Conclusion}

We have argued that a more nuanced understanding of the factors that can affect the building and maintaining of trust in PGT on different societal levels can better inform technical design decisions, ethical assessment, and policy-making. 
However, we must also acknowledge the challenges of adopting institutional lens in ethical deliberations. One particular challenge presented by the user-centric and institution-centric approaches to trust is that the task of building system-centric trust in technology is an enterprise requiring the involvement and participation of not only the end users and developers of technology but also multiple other stakeholders and interest groups such as technology assessors and ethicists, public policy makers, healthcare providers and so on. In our interconnected world, particular PGTs are frequently connected to or form part of, other technological systems and social networks operating under specific normative institutional jurisdictions. Given that attempts at building trust in one entity can be undermined by the pre-existing distrust of the overall system, the task of building system-centric task can potentially become a vastly complex collective endeavour. Consequently, we suggest as next steps for research in trust and persuasive gerontechnology:

(1) Investigating conceptually and empirically trust in relation to various factors shaping and affecting the adoption and use of PGTs.

(2) Studying the cognitive and social aspects of distinct forms of trust and trusting relations characteristic of the networks comprising the users, designers, and the wider community.

(3) Exploring multi-stakeholder models and approaches in the design and implementation of PGTs.

(4) Examining the dynamics and discourses of power and interests around persuasive gerontechnology.

A more thorough understanding of the role of trust in PGTs can ultimately lead to systems with PGTs that increase their user's well-being.

\section{References}

Allen, B.D. (2018). Serious Gaming for Building a Basis of Certification for Trust and Trustworthiness of Autonomous Systems. In 2018 Aviation Technology, Integration, and Operations Conference, Atlanta, Georgia, https://doi.org/10.2514/6.2018-3844.

Åm, T.G. (2011). Trust in nanotechnology? On trust as analytical tool in social research on emerging technologies. Nanoethics, 5, 15-28.

Andrews, G.R. (2001). Promoting health and function in an ageing population. British Medical Journal, 322, 728-729.

Atkinson, B.M.C. (2006). Captology: A critical review. In IJsselsteijn, W. et al. (eds.) Persuasive Technology. Berlin: Springer-Verlag, 171-182.

Audi, R. (2007). Some Dimensions of Trust in Business Practices: From Financial and Product Representation to Licensure and Voting. Journal of Business Ethics, 80, 97-102.

Baier, A. (1986). Trust and Antitrust. Ethics, 96(2), 231260.

Barnes, B. (1988). The Nature of Power. Cambridge: Polity.

Berdichevsky, D. \& Neuenschwander, E. (1999). Toward an Ethics of Persuasive Technology. Communications of the ACM, 42(5), 51-58.

Berridge, C. (2016). Breathing room in monitored space: The impact of passive monitoring technology on privacy in independent living. The Gerontologist, 56(5), 807-816.

Berridge, C. (2017). Active subjects of passive monitoring: Responses to a passive monitoring system in low-income independent living. Ageing \& Society, 37(3), 537-560.

Bok, S. (1979). Lying. New York: Vintage Books.

Bouma, H., Fozard, J.L. \& Van Bronswijk, J.E.M.H. (2009). Gerontechnology as a field of endeavour. Gerontechnology, 8(2), 68-75.

Bouma, H., Fozard, J.L., Bouwhuis, D.G. \& Taipale, V. (2007). Gerontechnology in perspective. Gerontechnology, 6(4), 190-216.

Bovens, L. (2009). The Ethics of Nudge. In Grüne-Yanoff, T. \& Hansson, S.O. (eds.) Preference Change: Approaches from Philosophy, Economics and Psychology. Dordrecht: Springer, 207-219.

Brey, P. (2000). Disclosive computer ethics. Computers and Society, December 2000, 10-16.

Brey, P. (2008). The technological construction of social power. Social Epistemology, 22(1), 71-95.

Brox, E., Hernandez, J.E.G. (2011). Exergames for elderly: Social exergames to persuade seniors to increase physical activity. In Proceedings of the 5th IEEE International Conference on Pervasive Computing Technology for Healthcare, Dublin, Ireland, 546-549.

Castilla, D., Garcia-Palacios, A., Miralles, I., BretonLopez, J., Parra, E., Rodriguez-Berges, S., \& Botella, C. (2016). Effect of Web navigation style in elderly users. Computers in Human Behavior, 55, 909-920.

Cattan, M., White, M., Bond. J. \& Allison, L. (2005). Preventing social isolation and loneliness among older people: a systematic review of health promotion interventions. Age \& Society, 25, 41-67.

Cheung, Ch. M.K. \& Lee, M.K.O. (2006). Understanding consumer trust in Internet shopping: a multidisciplinary approach. Journal of the American Society for Information Science and Technology, 57, 479-492.

Christman, J. (2004). Relational autonomy, liberal individualism, and the social constitution of selves. Philosophical Studies, 117(1), 143-164.

Churchill, L.R. (1989). Trust, autonomy, and advance directives. Journal of Religion and Health, 28, 175-183.

Clarkson, P.J., Coleman, R., Keates, S. \& Lebbon, C., (eds.) (2013). Inclusive design: Design for the whole population. London: Springer-Verlag.

Coeckelbergh, M. (2012). Growing Moral Relations: Critique of Moral Status Ascription. Basingstoke: Palgrave Macmillan.

Coleman, J. (1990). Foundations of social theory. Cambridge, MA: Harvard University Press.

Cook, K. S. (2005). Networks, norms, and trust: The Social Psychology of Social Capital. Social Psychol- 
ogy Quarterly, 68(1), 4-14.

Cozza, M., De Angeli, A., \& Tonolli, L. (2017). Ubiquitous technologies for older people. Personal and Ubiquitous Computing, 21(3), 607-619.

Darwall, S. (2017). Trust as a Second-Personal Attitude of the Heart. In Faulkner, P., \& Simpson, T. (eds.) The Philosophy of Trust. Oxford: Oxford University Press, 35-50.

de Barros, A. C., Leitão, R., and Ribeiro, J. (2014). Design and Evaluation of a Mobile User Interface for Older Adults: Navigation, Interaction and Visual Design Recommendations. Procedia Computer Science, 27, 369-378.

de Kort, YAW, et al. (2005). Editorial: Persuasive gerontechnology. Gerontechnology, 4(3), 123-127.

de Ruyter, K., Wetzels, M. \& Kleijnen, M. (2001). Customer adoption of e-services: an experimental study. International Journal of Service Industry Management, 12, 184-207.

Dimitrov, D.V. (2016). Medical internet of things and big data in healthcare. Healthcare Informatics Research, 22(3), 156-163.

Drewnowski, A. \& Evans, W.J. (2001). Nutrition, Physical Activity, and Quality of Life in Older Adults: Summary. Journals of Gerontology, 56A(II), 89-94.

Elliott, R.A., Goeman, D., Beanland, C., \& Koch, S. (2015). Ability of Older People with Dementia or Cognitive Impairment to Manage Medicine Regimens: A Narrative Review. Current Clinical Pharmacology, 10, 213-221.

Etters, L., Goodall, D. \& Harrison, B.E. (2008). Caregiver burden among dementia patient caregivers: A review of the literature. Journal of the American Academy of Nurse Practitioners, 20, 423-428.

Fogg, B.J. (2003) Persuasive technologies: Using computers to change what we think and do. San Francisco: Morgan Kauffman Publishers.

Forssbæck, J. \& Oxelheim, L. (2015). Multifaceted Concept of Transparency. In Forssbæck, J. \& Oxelheim, L. (eds.) The Oxford Handbook of Economic and Institutional Transparency. Oxford: Oxford University Press, 3-30.

Fozard, J.L. \& Kearns, W.D. (2006). Persuasive GERONtechnology: Reaping Technology's Coaching Benefits at Older Age. In IJsselsteijn, W. et al. (eds.) Persuasive Technology. Berlin: Springer-Verlag, 199-202.

Fozard, J.L., Rietsema, J., Bouma, H., \& Graafmans, J.A.M. (2000). Gerontechnology: Creating enabling environments for the challenges and opportunities of aging. Educational Gerontology, 26(4), 331-344.

Franssen, M. (2009). Artefacts and Normativity. In Meijers, A. (ed.) Handbook of the Philosophy of Science; Volume 9: Philosophy of Technology and Engineering Sciences. Amsterdam: Elsevier, 923-952.

Frewer, L. \& Salter, B. (2007). Societal trust in risk analysis: Implications for the interface of risk assessment and risk management. In Siegrist, M., Earl, T.C. \& Gutscher, H. (eds.) Trust in cooperative risk management: Uncertainty in scepticism in the public mind. London: Earthscan, 143-158.

Frewer, L. (2004). The public and effective risk communication. Toxicology Letters, 149(1), 391-397.
Friedman, B., Kahn Jr, P.H., Borning, A. \& Huldtgren, A. (2013). Value sensitive design and information systems. In Doorn, N., et al. (eds.) Early engagement and new technologies: Opening up the laboratory. Dordrecht: Springer, 55-95.

Friedman, M. (2000). Feminism in ethics: Conceptions of autonomy. In Fricker, M. \& Hornsby, J. (eds.) The Cambridge companion to feminism in philosophy. New York: Cambridge University Press, 205-220.

Frohlich, D., Thomas, P., Hawley, M., \& Hirade, K. (1997). Inaugural issue editorial: future personal computing. Personal Technologies, 1(1), 1-5.

Garlo, K., O'Leary, J.R., Van Ness, P.H., \& Fried, T.R. (2010). Caregiver Burden in Caregivers of Older Adults with Advanced Illness. Journal of American Geriatric Society, 58(12), 2315-2322.

Gefen, D. \& D. Straub (2003). Managing user trust in B2C e-services. E-Service Journal, 2, 7-24.

Giddens, A. (1990). The consequences of modernity. London: Polity Press.

Grabner-Kräuter, S. \& Kaluscha, E.A. (2008). Consumer trust in electronic commerce: conceptualization and classification of trust building measures. In Kautonen, T. \& Karjaluoto, H. (eds.) Trust and New Technologies Marketing and Management on the Internet and Mobile Media. Cheltenham, UK: Edward Elgar, 3-22.

Grabner-Kräuter, S. (2002). The role of consumers' trust in online shopping. Journal Business Ethics, 39, 43-50.

Hall, M.A. (2005). The importance of trust for ethics, law and public policy. Cambridge Quarterly of Healthcare Ethics, 14, 156-167.

Hansen, P.G. \& Jespersen, A.M. (2013). Nudge and the manipulation of choice: A framework for the responsible use of the nudge approach to behaviour change in public policy. European Journal of Risk Regulation, 4(1), 3-28.

Harada, S., Sato, D., Takagi, H., and Asakawa, C. (2013) Characteristics of Elderly User Behavior on Mobile Multi-Touch Devices. INTERACT 2013 Proceedings, Cape Town, South Africa, 323-341.

Hardin, R. (1991). Trusting persons, trusting institutions. In Zeckhauser, R. J. (ed.) Strategy and Choice. Cambridge, MA: The MIT Press, 185-209.

Hardin, R. (2002). Trust and trustworthiness. New York: The Russell Sage Foundation.

Hawthorn, D. (2000). Possible implications of aging for interface designers. Interacting with Computers, 12(5), 507-528.

Hébert, R. (1997). Functional decline in old age. Canadian Medical Association Journal, 157, 1037-1045.

Heeter, C., et al. (2003). Telewindows: Case studies in asymmetrical social presence. Emerging Communication, 5, 279-294.

Hollyer, J. R., Rosendorff, B. P., and Vreeland, J. R. (2011). Democracy and transparency. Journal of Politics, 73(4), 1-15.

Hu, W. L., Akash, K., Jain, N., \& Reid, T. (2016). Realtime sensing of trust in human-machine interactions. IFAC-PapersOnLine, 49(32), 48-53.

Ijsselsteijn, W., De Kort, Y., Midden, C., Eggen, B. \& Van Den Hoven, E. (2006). Persuasive technology for human well-being: setting the scene. In IJsselsteijn, W. et al. (eds.) Persuasive Technology. 
Berlin: Springer, 1-5.

Intille, S.S. (2004). A new research challenge: Persuasive technology to motivate healthy aging. IEEE Transactions on information technology in Biomedicine, 8(3), 235-237.

James, B.D., Wilson, R.S., Barnes, L.L., \& Bennett, D.A. (2011). Late-Life Social Activity and Cognitive Decline in Old Age. Journal International Neuropsychology Society, 17(6), 998-1005.

Jarvenpaa, S., Tractinsky, N. \& Vitale, M. (2000). Consumer trust in an Internet store. Information Technology and Management, 1, 45-71.

Jessop, B. (2001). Institutional re (turns) and the strategic-relational approach. Environment and Planning A, 33(7), 1213-1235.

Joyce, K., \& Loe, M. (2010). A sociological approach to ageing, technology and health. Sociology of Health \& Illness, 32(2), 171-180.

Kamimura, T. \& Ishiwata, R. (2012). Medication reminder device for the elderly with mild cognitive impairment. American Journal of Alzheimer's Disease \& Other Dementias, 27(4), 238-242.

Kellmeyer, P., Mueller, O., Feingold-Polak, R. \& LevyTzedek, S. (2018). Social robots in rehabilitation: A question of trust. Science Robotics, 3, eaat1587.

Keränen, N. S., Kangas, M., Immonen, M., Similä, H., Enwald, H., Korpelainen, R., \& Jämsä, T. (2017). Use of information and communication technologies among older people with and without frailty: a population-based survey. Journal of Medical Internet Research, 19(2). DOI:10.2196/jmir.5507.

Larburu, N., Widya, I., Bults, R., \& Hermens, H. (2013). Early phase telemedicine requirements elicitation in collaboration with medical practitioners. Proceedings of the Requirements Engineering Conference (RE), 21st IEEE International, 273-278.

Lee, C., \& Coughlin, J. F. (2015). PERSPECTIVE: Older adults' adoption of technology: an integrated approach to identifying determinants and barriers. Journal of Product Innovation Management, 32(5), 747-759.

Lewis, J.D., \& Weigert, A. (1985). Trust as a Social Reality. Social Forces, 63(4), 967-985.

Lin, Y. (2013). Motivate: a context aware mobile application for physical activity promotion. PhD Dissertation, Eindhoven University of Technology.

Lockton, D., Harrison, D. and Stanton, N., (2008). Design with intent: Persuasive technology in a wider context. In Oinas-Kukkonen, H. et al. (ed.) Persuasive 2008. Berlin: Springer Verlag, 274-278.

Luhmann N. (1979). Trust and Power. Chichester: John Wiley and Sons.

Lutz, W., Sanderson, W. \& Scherbov, S. (2008). The coming acceleration of global population ageing. Nature, 451, 716-719.

Mackenzie, C., \& Stoljar, N. (eds.) (2010). Relational autonomy: Feminist perspectives on autonomy, agency, and the social self. New York: Oxford University Press.

Mackenzie, C., Rogers, W., \& Dodds, S. (eds.) (2014). Vulnerability: New Essays in Ethics and Feminist Philosophy. Oxford: Oxford University Press.

Matthews, J., Win, K.T., Oinas-Kukkonen, H. \& Freeman, M. (2016). Persuasive technology in mobile appli- cations promoting physical activity: a systematic review. Journal of Medical Systems, 40(3), 72-85.

McCall, R., \& Baillie, L. (2017). Ethics, Privacy, and Trust in Serious Games. Nakatsu, R. et al. (eds.) Handbook of Digital Games and Entertainment Technologies. https://doi.org/10.1007/978-981-4560-52-8_37-1.

Mckee, K., Matlabi, H., \& Parker, S.G. (2012). Older People's Quality of Life and Role of Home-Based Technology. Health Promotion Perspectives, 2(1), $1-8$.

McLeod, C. (2002). Self-trust and reproductive autonomy. Cambridge, MA: MIT Press.

McMurray, J., Strudwick, G., Forchuk, C., Morse, A., Lachance, J., Baskaran, A., \& Booth, R. (2017). The Importance of Trust in the Adoption and Use of Intelligent Assistive Technology by Older Adults to Support Aging in Place: Scoping Review Protocol. JMIR Research Protocols, 6(11). DOI: 10.2196/resprot.8772.

Melenhorst, A.S. (2002). Adopting communication technology in later life: The decisive role of benefits. PhD Dissertation, Eindhoven University of Technology.

Meyers, D.T., (2005). Decentralizing autonomy: Five faces of selfhood. In Christman, J. \& Andrews, J. (eds.) Autonomy and the Challenges to Liberalism. Cambridge: Cambridge University Press, 27-55.

Michelfelder, D.P., Wellner, G. \& Wiltse, H. (2017). Designing Differently: Toward a Methodology for an Ethics. In Hansson, S.O. (ed.) The Ethics of Technology: Methods and Approaches. London: Rowman \& Littlefield, 193-218.

Mollenkopf, H. \& Walker, A. (2007). International and Multi-Disciplinary Perspectives on Quality of Life in Old Age. In Mollenkopf, H. \& Walker, A. (eds.) Quality of Life in Old Age: International and MultiDisciplinary Perspectives. Dordrecht: Springer, 3-13.

Muller, M.J. and Kuhn, S., (1993). Participatory design. Communications of the ACM, 36(6), 24-28.

Nagel, S.K. (2015). When Aid is a Good Thing - Trusting Relationships as Autonomy Support in Health Care Settings. American Journal of Bioethics, 15(10), 49-51.

Nagel, S.K. (in press). Zwischen Autonomie und Abhängigkeit: die Bedeutung von Beziehung und Vertrauen in der Pflege. In Hülsken-Giesler, M. et al. (eds.) Neue Technologien in der Pflege - Grundlegende Reflexionen und pragmatische Befunde. Vandenhoeck \& Ruprecht.

Nagenborg, M. (2014). Surveillance and Persuasion. Ethics \& Information Technology, 16, 43-49.

Nedelsky, J. (1989). Reconceiving autonomy: Sources, thoughts and possibilities. Yale Journal of Law \& Feminism, 1(1), 7-36.

Nelson, R. R. (2008). What enables rapid economic progress: What are the needed institutions?. Research Policy, 37(1), 1-11.

Nickel, P. (2011). Ethics in e-trust and e-trustworthiness: the case of direct computer-patient interfaces. Ethics \& Information Technology, 13, 355-363.

Nickel, P. (2013). Trust in Technological Systems. In de Vries, M.J. et al. (eds.) Norms in Technology, Philosophy of Engineering and Technology, 9, 
Dordrecht: Springer, 223-237.

Nickel, P. (2015). Design for the value of trust. In van den Hoven, J. et al. (eds.) Handbook of Ethics, Values, and Technological Design. Dordrecht: Springer, 551-567.

Nickel, P., \& Spahn, A. (2012). Trust, Discourse Ethics, and Persuasive Technology. In Persuasive Technology: Design for Health and Safety, PERSUASIVE 2012, the 7th International Conference on Persuasive Technology, Adjunct Proceedings no. 068, Linköping, Sweden, June 6-8, 37-40.

Nickel, P., Franssen, M. \& Kroes, P. (2010). Can We Make Sense of the Notion of Trustworthy Technology?. Knowledge Technology \& Policy, 23, 429-444.

Nielsen, K. (2007). The institutional turn in the social sciences: A review of approaches and a future research agenda. In loannides, S. \& Nielsen, K. (eds.) Economics and the Social Sciences. Boundaries, Interaction and Integration. Cheltenham: Edward Elgar, 91-111.

Niker, F. \& Specker Sullivan, L. (2018). Trusting Relationships and the Ethics of Interpersonal Action. International Journal of Philosophical Studies, 26(2), 173-186.

Niker, F. (2017). Living well by design: an account of permissible public nudging. PhD Dissertation, University of Warwick.

O'Connor, C. \& Nagel, S.K. (2017). Neuro-enhancement practices across the lifecourse: Exploring the roles of relationality and individualism. Frontiers in Sociology, 2, https://doi.org/10.3389/fsoc.2017.00001

O'Neill, O. (2002). Autonomy and Trust in Bioethics. Cambridge: Cambridge University Press.

Oeppen, J. \& Vaupel, J.W., (2002). Broken limits to life expectancy. Science, 296(5570), 1029-1031.

Östlund, B. (2015). The benefits of involving older people in the design process. In International Conference on Human Aspects of IT for the Aged Population. Springer, Cham, 3-14.

Östlund, B., Olander, E., Jonsson, O., \& Frennert, S. (2015). STS-inspired design to meet the challenges of modern aging. Welfare technology as a tool to promote user driven innovations or another way to keep older users hostage?. Technological Forecasting and Social Change, 93, 82-90.

Pak, R., Fink, N., Price, M., Bass, B. \& Sturre, L. (2012). Decision support aids with anthropomorphic characteristics influence trust and performance in younger and older adults. Ergonomics, 55(9), 1059-1072.

Pal, D., Funilkul, S., Charoenkitkarn, N., \& Kanthamanon, P. (2018) Internet-of-Things and Smart Homes for Elderly Healthcare: An End User Perspective. IEEE Access, 6, 10483-10496.

Pasikowska, A., Zaraki, A., \& Lazzeri, N. (2013). A dialogue with a virtual imaginary interlocutor as a form of a psychological support for well-being. In Proceedings of the ACM International Conference on Multimedia, Interaction, Design and Innovation, Warsaw, Poland, 24-25 June 2013.

Patsoule, E., \& Koutsabasis, P. (2014). Redesigning Websites for Older Adults: A Case Study. Behaviour \& Information Technology, 33:6, 561-573.

Penninx, B., Deeg, D., van Eijk, J., Beekman, A. \& Guralnik, J. (2000). Changes in depression and physi- cal decline in older adults: a longitudinal perspective. Journal of Affective Disorders, 61, 1-12.

Pettit, P. (1995). The cunning of trust. Philosophy and Public Affairs, 24(3), 202-225.

Ponce, V., Deschamps, J.P., Giroux, L.P., Salehi, F., \& Abdulrazak, B. (2015). QueFaire: Context-aware in-person social activity recommendation system for active aging. In Proceedings of the International Conference on Smart Homes and Health Telematics, Geneva, Switzerland, 64-75.

Poortinga, W. \& Pidgeon, N.F. (2005). Trust in Risk Regulation: Cause or Consequence of the Acceptability of GM Food? Risk Analysis, 25(1), 199-209.

Pyae, A., Liukkonen, T.N., Mika, L., Kattimeri, C., Cauberghe, V. \& Smed, J. (2017). Investigating the Finnish elderly people's attitudes and motivation towards digital game-based physical exercises. Finnish Journal of eHealth and eWelfare, 9(4), 265-283.

Rhodes, R. A., Binder, S. A., \& Rockman, B. A. (Eds.). (2008). The Oxford handbook of Political Institutions. Oxford University Press.

Robertson, T., \& Simonsen, J. (2012). Participatory Design: an introduction. In Simonsen, J. \& Robertson, T. (ed.) Routledge International Handbook of Participatory Design. London: Routledge, 21-38.

Ruer, P., Gouin-Vallerand, C. \& Vallières, E.F. (2016). Persuasive strategies to improve driving behaviour of elderly drivers by a feedback approach. In Meschtscherjakov, A. et al. (eds.) PERSUASIVE 2016, International Conference on Persuasive Technology, Cham: Springer, 110-121. DOI: 10.1007/9783-319-31510-2_10.

Sayago, S., \& Blat, J. (2011a). An ethnographical study of the accessibility barriers in the everyday interactions of older people with the web. Universal Access in the Information Society, 10(4), 359-371.

Sayago, S., Sloan, D., \& Blat, J. (2011b). Everyday use of computer-mediated communication tools and its evolution over time: An ethnographical study with older people. Interacting with Computers, 23(5), 543-554.

Searle, J. R. (2005). What is an Institution?. Journal of Institutional Economics, 1(1), 1-22.

Sengers, P., Boehner, K., David, S. \& Kaye, J. (2005). Reflective Design. In Proceedings of the 4th Decennial Conference on Critical Computing: Between Sense and Sensibility, New York: ACM, 49-58.

Sherlock, R. (1986). Reasonable men and sick human beings. American Journal of Medicine, 80, 2-4.

Siegrist, M. (2000). The Influence of Trust and Perceptions of Risks and Benefits on the Acceptance of Gene Technology. Risk Analysis, 20(2), 195-203.

Siegrist, M. (2007). Public acceptance of nanotechnology foods and food packaging: The influence of affect and trust. Appetite, 49, 459-466.

Sorell, T. \& Draper, H. (2012). Telecare, Surveillance and the Welfare State. The American Journal of Bioethics, 12(9), 36-44.

Sorell, T. (2011). The limits of principlism and recourse to theory: The example of telecare. Ethical Theory and Moral Practice, 14, 369-382.

Sorri, L. \& Leinonen, E. (2008). Technology that persuades the elderly. In Oinas-Kukkonen, H. et al. (eds.) Persuasive 2008. Berlin: Springer-Verlag, 270-273.

Spahn, A. (2012). And Lead Us (Not) into Persuasion...? 
Persuasive Technology and the Ethics of Communication. Science and Engineering Ethics, 18(4), 633-650.

Thaler, R.H. \& Sunstein, C.R. (2008). Nudge: Improving Decisions about Health, Wealth and Happiness. New Haven, CT: Yale University Press.

The Economist. (2018). America should borrow from Europe's data-privacy law. 5 April 2018. Retrieved from: https://www.economist.com/leaders/2018/04/05/america-should-borrow-from-europes-data-privacy-law

Thommessen, B., Aarsland, D., Braekhus, A., Oksengaard, A.R., Engedal, K., \& Laake, K. (2002). The psychosocial burden on spouses of the elderly with stroke, dementia and Parkinson's disease. International Journal of Geriatric Psychiatry. 17, 78-84.

Thompson, D. F. (1999). The institutional turn in professional ethics. Ethics \& Behavior, 9(2), 109-128.

Tinker, A. (2002). The social implications of an ageing population. Mechanisms of Ageing and Development. 123, 729-735.

Tsiourti, C., Moussa, M.B., Quintas, J., Loke, B., Jochem, I., Lopes, J.A. \& Konstantas, D. (2016). A virtual assistive companion for older adults: design implications for a real-world application. In Bi, Y. et al (eds.) Proceedings of SAI Intelligent Systems Conference. Cham: Springer, 1014-1033.

United Nations, Department of Economic \& Social Affairs, Population Division (2013). World Population Ageing 2013. Retrieved from: http://www.un.org/ en/development/desa/population/publications/pdf/ ageing/WorldPopulationAgeing2013.pdf

Van Bronswijk, J.E., Bouma, H., Fozard, J.L., Kearns, W.D., Davison, G.C. \& Tuan, P.C., (2009). Defining gerontechnology for R\&D purposes. Gerontechnology, 8(1), 3-10.

Van de Poel, I. \& Verbeek, P-.P. (2006). Ethics and Engineering Design. Science, Technology, \& Human Values, 31(3), 223-236.

Verbeek, P-.P. (2005). What things do: philosophical reflections on technology, agency, and design. Pennsylvania: Pennsylvania State University Press.

Voerman, S. \& Nickel, P. (2017). Sound Trust and the Ethics of Telecare'. Journal of Medicine and Philosophy, 42(1), 33-49.

Wang, N., Broz, F., Di Nuovo, A., Belpaeme, T., Cangelosi, A. (2016). A User-Centric Design of Service Robots Speech Interface for the Elderly. In Recent Advances in Nonlinear Speech Processing, Cham, Switzerland: Springer, 275-283.

Wiesemann C. (2017). On the Interrelationship of Vulnerability and Trust. In Straehle, C. (ed.) Vulnerability, Autonomy and Applied Ethics. New York: Routledge, 157-170

Wiesemann, C. (2016). Moral Equality, Bioethics, and the Child. Springer.

Winner, L. (1980). Do artifacts have politics?. Daedalus, $109(1), 121-136$.

World Health Organization (2015). World Report on Aging and Health. Retrieved from: http://apps.who.int/ iris/bitstream/10665/186463/1/9789240694811_ eng.pdf

World Health Organization, Regional Office for Europe (2012) Policies and priority interventions for healthy aging. Retrieved from: http://www. euro.who.int/__data/assets/pdf_file/0006/161637/ WHD-Policies-and-Priority-Interventions-forHealthy-Ageing.pdf?ua=1 